\title{
Perbedaan Individual pada Ideologi Politik Berbasis Agama
}

\author{
IImi Amalia \\ Fakultas Psikologi UIN Jakarta \\ ilmi.amalia@uinjkt.ac.id
}

\begin{abstract}
In practicing worship almost all Muslims run in the same manner but in Indonesia also found the diversity of the face of Islam. One form of diversity is how to see religion as a political ideology. From various views political ideologies based on Islamic religion have polarizations, namely secular and radical Islamism. How to explain the diversity of ideologies based on individual differences. Jost et al (2009) offer three basic needs that determine individual ideological differences, namely the need for epistemic, the need for existential, and the need for relation. In addition to differences in the concept of fundamental needs, studies also show a relationship between personality types and ideological or political attitudes. Duckitt \& Sibley (2010) offers a dual-process motivational model that explains that political ideology is formed due to interactions between personalities and different social situations. Many studies have been conducted to see the relationship between ideology with liberal and conservative polarization (right / left) or right wing authoritarianism $(R W A)$ and social dominance orientation (SDO) with different needs or personality types (Jost, Ledgerwood, \& Hardin, 2008; Jost et al., 2007; Sibley, Osborne, \& Duckitt, 2012). However, no research has been conducted on political ideologies based on religion, especially Islam. The purpose of this study is to look at the influence of the Big Five Personality, need for epistemic, need for existential and need for relation to Islamic political ideology. The study was conducted on 243 Muslims and aged 17 years and over. Questionnaires were distributed in the Greater Jakarta area online and offline. The sampling technique used convenience sampling. Then the data is processed using regression analysis techniques. The results showed that together, the need for epistemic, need for existential, need for relation, and Big Five Personality influenced Islamic political ideology with a contribution of 7.2\%. Significant predictors of the relationship are need for existential and need for relation.
\end{abstract}

Keywords: political ideology, secular, radical Islamism, need for epistemic, need for existential, need for relation, Big Five Personality

\begin{abstract}
Abstrak
Dalam pelaksanaan ibadah hampir semua umat Islam menjalankan dengan tata cara yang sama namun di Indonesia ditemukan juga keanekaragaman wajah Islam. Salah satu bentuk keanekaragaman tersebut adalah bagaimana melihat agama sebagai suatu ideologi politik. Dari berbagai macam pandangan dapat dilihat bahwa ideologi politik yang berbasis agama Islam memiliki polarisasi yaitu sekuler dan radikal Islamisme. Bagaimana menjelaskan keragaman ideologi tersebut berdasarkan perbedaan individual. Jost dkk (2009) menawarkan adanya tiga kebutuhan mendasar yang menentukan perbedaan ideologi individu yaitu need for epistemic, need for existential, dan need for relation. Selain pada perbedaan pada konsep kebutuhan mendasar, studi juga menunjukkan adanya hubungan tipe kepribadian dan ideologi atau sikap politik. Duckitt \& Sibley (2010) menawarkan model dual-process motivational yang menjelaskan bahwa ideologi politik terbentuk akibat interaksi antara kepribadian dan situasi sosial yang berbeda. Studi telah banyak dilakukan untuk melihat hubungan ideologi dengan polarisasi liberal dan konservatif (kanan/kiri) atau right wing authoritarianism (RWA) dan social dominance orientation (SDO) dengan perbedaan kebutuhan atau tipe
\end{abstract}


kepribadian (Jost, Ledgerwood, \& Hardin, 2008; Jost et al., 2007; Sibley, Osborne, \& Duckitt, 2012). Namun demikian, belum ada riset yang dilakukan pada ideologi politik yang berlandaskan pada agama terutama Islam. Tujuan penelitian ini untuk melihat pengaruh Big Five Personality, need for epistemic, need for existential dan need for relation terhadap ideologi politik Islam. Studi dilakukan pada 243 Muslim dan berumur 17 tahun ke atas. Kuesioner disebarkan di daerah Jabodetabek secara daring dan luring. Teknik pengambilan sampel digunakan convenience sampling. Kemudian data diolah dengan teknik analisis regresi. Hasil penelitian menunjukkan secara bersama-sama, need for epistemic, need for existential, need for relation, dan Big Five Personality mempengaruhi ideologi politik Islam dengan kontribusi sebesar 7,2 \%. Prediktor yang signifikan hubungannya adalah need for existential dan need for relation.

Kata Kunci: ideologi politik, sekuler, radikal Islamisme, need for epistemic, need for existential, need for relation, Big Five Personality

\section{Pendahuluan}

Studi menunjukkan bahwa Islam di Indonesia memiliki beraneka ragam terutama dalam ideologi politiknya (Fauzia et al., 2011; Sakai \& Fauzia, 2014). Ideologi politik dapat didefinisikan sistem kepercayaan yang dimiliki individu yang pada umumnya dibagi pada kelompok tertentu, yang kemudian mengorganisir, memotivasi, dan memberi makna pada perilaku politik (Jost, 2006). Dari berbagai macam pandangan dapat dilihat bahwa ideologi politik yang berbasis agama Islam memiliki polarisasi yaitu sekuler dan radikal Islamisme. Sekuler dapat didefinisikan bahwa agama tidak dapat mengatur pengelolaan negara, sedangkan radikal Islamisme menganggap bahwa agama mengatur semua aspek kehidupan termasuk negara (Shepard, 1987).

Perbedaan ideologi ditingkat elit dan pemimpin juga diikuti oleh masyarakat pada umumnya. Banyak ditemukan orang-orang yang merasa nyaman mengikuti pengajian atau organisasi tertentu karena adanya kesamaan pandangan. Jost, Federico, \& Napier (2009) menawarkan konsep elective affinity yang menunjukkan adanya proses bottom up dan top down. Proses top down dilakukan olah para elit politik yang mengkonstruksi dan mendiseminasikan pemikiran kepada masyarakat. Kemudian, terjadi proses psikologis dari individu untuk menentukan ideologi yang diyakininya. Jost dkk (2009) menawarkan adanya tiga kebutuhan yang menentukan perbedaan ideologi individu yaitu need for epistemic, need for existential, dan need for relation.

Need for epistemic mengacu pada kebutuhan unutk mendapatkan kepastian, konsistensi, dan makna, mengacu pada lay epistemic theory (Jost et al., 2003). Pada model yang ditawarkan Jost dkk (2009) need epistemic terdiri dari Need for cognition, need to evaluate, dan need for cognitive closure. Need for cognition adalah kebutuhan untuk berpikir, menalar atas semua peristiwa yang terjadi. Pada umumnya individu yang memiliki ideologi liberal akan memiliki Need for cognition yang cukup tinggi. Need to evaluate mengacu pada kebutuhan untuk menilai suatu hal atau pengalaman baik atau buruk. Pada individu yang konservatif akan memiliki kebutuhan yang tinggi untuk menilai suatu kejadian. Sedangkan need for cognitive closure mengacu pada motivasi untuk mencari sistem kepercayaan yang menyederhanakan, menjelaskan, dan menawarkan kepastian dalam menjelaskan peristiwa.

Existential need mengacu pada kebutuhan manusia untuk mengurangi ancaman dan stres. Konsep ini berakar dari terror management theory yang menyatakan bahwa ideologi atau cultural worldview memiliki fungsi eksistensial yang secara simbolik mentransenden ancaman akibat kesadaran manusia akan kematian (Jost dkk ,2009). 
Need for relation mengacu kebutuhan untuk mengatur hubungan sosial dan dapat berbagi realita dengan orang lain. Konsep ini berakar pada teori share reality yang dikemukakan oleh Hardin and Higgins (1996). Teori ini menyatakan bahawa individu termotivasi untuk mencapai kesepakatan atau berbagai realita dengan individu lain dengan tujuan (i) mendirikan, memantapkan, dan mengatur hubungan interpersonal dengan kata lain memuaskan kebutuhan akan afiliasi, (ii) mempersepsikan diri dan lingkungan sebagai sesuatu yang stabil, dapt diprediksi, dan terkontrol. Menurut teori ini dua hal yang penting bagai manusia agar dapat bertahan hidup, bersosialisasi dan pengetahuan tentang dunia luar, dapat dipenuhi dengan mekanisme yang sama yaitu berbagi realita dalam hubungan interpersonal.

Dalam model yang ditawarkan oleh Jost dkk (2009) perbedaan dari ketiga kebutuhan tersebut dapat menyebabkan terjadi perbedaan pilihan ideologi. Ideologi dijelaskan dalam kerangka teori motivasi, ketiga kebutuhan ada pada lapisan motivasional substruktur. Komposisi yang berbedabeda dari ketiga kebutuhan tersebut akan menyusun lapisan superstruktur diskursif yang terdiri dari diskursus keterbukaan versus resisten terhadap perubahan dan penerimaan versus penolakan terhadap ketidaksetaraan. Diskursus tersebut menggambarkan ideologi politik liberal/konservatif. Ideologi tersebut kemudian memotivasi berbagai perilaku dan sikap politik.

Studi meta analisis yang dilakukan oleh Jost, Glaser, Kruglanski, \& Sulloway (2003) menunjukkan bahwa konservatif berhubungan dengan death anxiety (weighted mean $\mathrm{r} 0.50$ ); system instability (0.47); dogmatism-intolerance of ambiguity (0.34); Openness to experience (-0.32); uncertainty tolerance ( -0.27$)$; needs for order, structure, and closure (0.26); integrative complexity $(-0.20)$; fear of threat and loss (0.18); dan harga diri (-0.09). Selain itu, studi lainnya menunjukkan bahwa kebutuhan untuk berpikir secara sederha berhubungan dengan ideologi right-wing authoritarianism (Jugert, Cohrs, \& Duckitt, 2009). Hennes, Nam, Stern, \& Jost (2012) dalam penelitiannya menemukan bahwa ada hubungan ideologi system justification dengan kebutuhan akan kognisi, kecemasan akan kematian, dan kebutuhan berbagi dengan realita. Berbagai penelitian tersebut menjadi bukti empiris yang mendukung hubungan ketiga kebutuhan mendasar manusia dengan pilihan ideologi.

Selain pada perbedaan pada konsep kebutuhan, studi juga menunjukkan adanya hubungan tipe kepribadian dan ideologi atau sikap politik. Duckitt \& Sibley (2010) menawarkan model dualprocess motivational yang menjelaskan bahwa ideologi politik memiliki dua sikap ideologi yaitu right wing authoritarianism (RWA) dan social dominance orientation (SDO). Kedua sikap ini terbentuk karena adanya dua pandangan hidup yang berbeda melihat dunia sebagai berbahaya atau kompetitif. Pandangan hidup yang berbeda merupakan interaksi antara kepribadian dan situasi sosial yang berbeda. Kepribadian di sini adalah melihat social conformity dan tough-mindedness.

Studi meta analisis oleh Sibley, Osborne, \& Duckitt (2012) menunjukkan trait Openness to experience dan conscientiousness memiliki hubungan yang signifikan dengan ideologi konservatisme. Dengan menggunakan tipologi kepribadian yang berbeda, Verhulst, Hatemi, \& Martin, (2010) juga menunjukkan bahwa psychoticism berhubungan konservatif dan social desirability berhubungan dengan liberal. Hal ini menunjukkan bahwa kepribadian memiliki pengaruh terhadap pemilihan ideologi.

Studi-studi yang dilakukan hanya pada ideologi dengan polarisasi liberal dan konservatif (kanan/kiri) atau RWA dan SDO. Namun demikian, belum ada riset yang dilakukan pada ideologi politik yang berlandaskan pada agama terutama Islam. Jost et al. (2013) menyatakan agama tidak hanya suatu mekanisme berpikir untuk menjelaskan keterbatasan manusia dalam berkehendak, tetapi juga memiliki fungsi sebagai social-motivasional atau ideologi. Jost et al (2013) menyatakan 
agama dianalogikan memiliki fungsi yang sama dengan ideologi system justification. Hal ini berarti menyakini agama membuat individu cenderung termotivasi unutk mempertahankan, mendorong, dan menjustifikasi pengaturan sosial, ekonomi, dan politik yang ada. Walaupun demikian belum ada studi empiris yang menggunakan ideologi berbasis agama secara langsung, terutama khusus mengenai agama Islam. Hal lain yang perlu dipertimbangkan sehingga agama tidak bisa langsung dianalogikan dengan ideologi system justification adalah karena isi agama tidak hanya konservatif tetapi juga tema-tema progresif. Oleh karena itu berdasarkan pemaparan di atas maka dilakukan penelitian dengan permasalahan apakah ada pengaruh Extraversion trait, Agreeableness trait, conscientiousness trait, Emotional Stability trait, Openness trait, need for epistemic, need for existentialist, dan need for relation pada ideologi politik berbasis agama Islam?

\section{Metode}

Subjek pada penelitian ini adalah beragama Islam dan berumur minimal 17 tahun berjumlah 243 orang.Partisipan mengerjakan kuesioner yang disebarkan secara daring dan luring, terdiri lima skala. Instrumen yang digunakan untuk mengukur ideologi agama menggunakan Religious Intensity Scale yang dikembangkan oleh Hassan (2015). Skala ini terdiri dari beberapa indikator yaitu bagaimana individu melihat Quran dan Sharia, bagaimana melihat posisi perempuan di masyarakat, seberapa penting nilai syariah dalam sistem hukum, apakah hukum Islam harus dilaksanakan, dan sejauh pemikiran bahwa identitas Islam hanya dapat dipertahankan melalui ketaatan pada nilai-nilai Islam tradisional. Pada awalnya skala ini terdiri dari 20 item, namun dengan alasan kepraktisan maka pada penelitian ini hanya digunakan 14 item dengan pilihan jawaban 1 sampai dengan 5.

Untuk skala kepribadian digunkan Ten-Item Personality Inventory (TIPI) yang dikembangkan oleh Gosling, Rentfrow, dan Swann (2003). Inventori ini telah diadaptasi ke dalam bahasa Indonesia oleh (Akhtar, 2018). Inventori ini terdiri dari 10 item dan masing-masing trait diwakil oleh dua item. Cara menjawabnya adalah dengan memilihi angka 1 sampai dengan 7. Penelitian oleh Akhtar (2018) menunjukkan bahwa alat ukur ini tidak memiliki koefisien Cronbach alpha yang terlalu tinggi namun memiliki koefisien test retest yang cukup baik. Koefisien reliabilitas Cronbach alpha adalah 0.71 untuk Extraversion, 0.31 untuk Agreeableness, 0.30 untuk Conscientiousness, 0.65 untuk Emotional Stability, dan 0.34 untuk Openness. Reliabilitas koefisien test-retest adalah 0.85 untuk Extraversion, 0.79 untuk Agreeableness, 0.71 untuk Conscientiousness, 0.74 untuk Emotional Stability, dan 0.75 untuk Openness.

Untuk mengukur Need for epistemic digunakan Need for cognition scale yang dikembangkan oleh Cacioppo, Petty, \& Kao (1984). Need for cognition adalah trait kepribadian yang bersifat stabil yang menggambarkan kecenderungan individu untuk terlibat dan menikmati aktivitas kognitif (Cacioppo \& Petty, 1982). Need for cognition scale memiliki 16 item dengan cara menjawab memilih lima pilihan jawaban dari "sangat tidak seperti saya" sampai dengan "sangat seperti saya". Need for cognition scale memiliki internal konsistensi yang cukup tinggi dengan reliabilitas yang bervariasi antara $\alpha=.80$ dan $\alpha=.90$ (Cacioppo et al., 1996).

Untuk mengukur existentialist digunakan death anxiety scale yang dikembangkan oleh (Thorson \& Powell, 1992). Skala ini disusun berdasarkan teori dua faktor kecemasan akan kematian (Templer, 1976). Skala ini memiliki 25 item dengan cara menjawab yaitu memilih lima pilihan jawaban dari sangat tidak setuju sampai dengan sangat setuju. Studi oleh Thorson dan Powell (1992) menunjukkan bahwa skala ini memiliki koefisien Alpha Cronbach yang cukup baik sebesar 0.83 . 
Untuk mengukur need for relation digunakan need to belong scale yang dikembangkan oleh (Leary, Kelly, Cottrell, \& Schreindorfer, 2013). Skala ini dibuat berdasarkan pengamatan bahwa manusia banyak menghabiskan waktu bersama lainnya. Manusia memiliki kebutuhan untuk menjalin dan mempertahankan hubungan bahkan dalam jumlah yang minimal ketika menjalin hubungan interperonal (Baumeister \& Leary, 1995). Skala ini dibuat untuk mengukur kebutuhan tersebut, terdiri dari 10 item dan memiliki koefisien Alpha Cronbach yang cukup baik yaitu 0,8. Cara menjawab adalah dengan memilih lima pilihan jawaban yaitu sangat setuju sampai dengan sangat tidak setuju.

\section{Hasil}

Masalah utama yang ingin dijawab dalam penelitian ini adalah bagaimana kontribusi pengaruh Extraversion trait, Agreeableness trait, conscientiousness trait, Emotional Stability trait, Openness trait, need for epistemic, need for existentialist, dan need for relation terhadap ideologi politik berbasis agama Islam. Hasil pengolahan data menunjukkan bahwa Extraversion trait, Agreeableness trait, conscientiousness trait, Emotional Stability trait, Openness trait, need for epistemic, need for existentialist, dan need for relation berpengaruh terhadap ideologi politik berbasis agama $(\mathrm{p}<0.05)$. Hasil penelitian menunjukkan secara bersama-sama semua variabel independen mempengaruhi ideologi politik Islam dengan kontribusi sebesar $7.2 \%$. Secara parsial variabel independen yang berpengaruh adalah need for relation dengan koefisien regresi sebesar $0.176(\mathrm{p}<0.05)$ dan need for existentialist dengan koefisien regresi sebesar $-0.13(\mathrm{p}<0.05)$.

Tabel 1. R-Square terhadap Ideologi Politik Islam

\begin{tabular}{lllll}
\hline Model & R & R Square & Adjusted R Square & Std. Error of the Estimate \\
\hline 1 & $.269^{\mathrm{a}}$ & .072 & .040 & 9.12998 \\
\hline
\end{tabular}

Tabel 2. Signifikansi Hasil Analisis Regresi Ideologi Politik Islam

\begin{tabular}{llccccc}
\hline Model & & Sum of Square & Df & Mean Square & F & Sign. \\
\hline 1. & Regression & 1517.751 & 8 & 189.719 & 2.276 & $.023^{\text {b }}$ \\
& Residual & 19505.411 & 234 & 83.356 & & \\
& Total & 21023.162 & 242 & & & \\
\hline
\end{tabular}

Tabel 3. Koefisien Regresi terhadap Ideologi Politik Islam

\begin{tabular}{llll}
\hline Model & $\mathrm{B}$ & $\mathrm{T}$ & Sig. \\
\hline (Constant) & 47.897 & 6.762 & .000 \\
Need for relation & .176 & 2.445 & $.015^{*}$ \\
Need for epistemic & -.037 & -.539 & .590 \\
Need for existentialist & -.130 & -2.196 & $.029 *$ \\
Extraversion & .120 & .552 & .581 \\
Agreeableness & .377 & 1.128 & .260 \\
Conscientiousness & .514 & 1.556 & .121 \\
Emotion stability & -.231 & -.774 & .440 \\
Openness & -.613 & -1.953 & .052 \\
\hline
\end{tabular}

\section{Diskusi}


Hasil penelitian menunjukkan bahwa secara bersama-sama tipe kepribadian dan kebutuhan memprediksi ideologi berbasis agama. Hal ini sesuai dengan kerangka teori motivational ideologi (Jost et al., 2009) dan dual-process motivational model (Duckitt \& Sibley, 2010) yang menjelaskan bahwa ideologi politik memiliki dasar kepribadian. Walaupun demikian $r$ square yang kecil menunjukkan bahwa kepribadian bukan prediktor langsung dari ideologi politik. Dibutuhkan variabel mediator atau moderator yang dapat memperkuat pilihan ideologi politik.

Variabel Big Five Personality semuanya tidak bisa memprediksi pilihan ideologi. Hal ini sejalan dengan hasil meta analisis oleh Sibley et al., (2012) yang menunjukkan korelasi yang lemah namun signifikan dari Openness to experience dan conscientiousness terhadap ideologi politik konservatis. Pada penelitian selanjutnya maka hubungan itu akan semakin kuat ketika diinteraksi dengan variabel situasi sosial yang terancam.

Need for epistemic terbukti tidak berpengaruh terhadap ideologi, hasilnya yang berbeda apa bila dibandingkan hubungan dengan ideologi konservatisme. Hal ini menunjukkan bahwa menjadikan prinsip Islam mengatur seluruh aspek kehidupan belum tentu juga akan memudahkan seseorang dalam memahami dan menjelaskan dalam segala peristiwa dalam hidupnya.

Sesuai dengan yang diduga, need for existentialist memprediksi ideologi politik berbasis agama. Arah hubungannya menjadi khas karena berbeda dengan argumen yang dikemukan oleh Jost et al. (2013) yang menyatakan bahwa agama berfungsi sama seperti ideologi system justification seperti konservatisme, right-wing authoritarian. Semakin besar kecemasan akan kematian akan membuat individu semakin konservatif untuk mempertahankan eksistensi dirinya. (Vail et al., 2010) juga menyatakan bahwa dalam situasi terancam individu akan lebih memilih sistem kepercayaan yang religius daripada sistem sekuler, sebagai strategi menghadapi rasa cemas atau takut. Namun demikian, di satu sisi dapat memungkinkan terjadi hubungan yang sebaliknya. Kebutuhan untuk mengurangi kecemasan akan kematian justru berkurang pada individu dengan ideologi Islamisme yang tinggi. Hal ini terjadi karena individu dengan Islamisme yang tinggi sangat memahami kematian dalam Islam sehingga tidak ada hal-hal yang perlu dikuatirkan.

Need for relation juga memprediksi ideologi politik berbasis agama, semakin tinggi kebutuhannya maka semakin tinggi Islamismenya. Hal ini dapat dijelaskan bahwa agama adalah konstruk yang multidimensi (Saroglou, 2011). Agama memiliki dimensi personal sekaligus juga kolektif. Secara identitas, agama adalah identitas personal dan kolektif (Ysseldyk, Matheson, \& Anisman, 2010). Islam juga memiliki banyak ajaran yang memerintahkan pemeluknya untuk memperhatikan pemeluk Islam lainnya. Dalam Islamisme juga ada konsep ummah yang menyakini bahwa umat Islam di seluruh dunia adalah satu kesatuan.

Implikasi penelitian ini adalah untuk para penyelenggara negara di Indonesia agar dapat bisa lebih memahami dinamika politik umat Islam. Pada umumnya umat Islam Indonesia sudah mengakui Pancasila dan demokrasi sebagai sistem poltik, namun ada segelintir orang yang masih memperjuangkan negara berbasis Islam (Sakai \& Fauzia, 2014). Hasil penelitian menunjukkan bahwa berkembangnya ideologi Islamisme tidak hanya disebabkan sosialisasi dan internalisasi yang intesif dari para pemimpin atau tokoh, tetapi juga disebabkan karena adanya kebutuhan psikologis dari individu terutama need of relational dan need of existentialist. Untuk menyingkapi itu, maka pemerintah atau pemuka agama dapat mensosialisasi Islam sedemikian rupa sehingga memenuhi kebutuhan tersebut, namun tetap dalam koridor Negara Kesatuan Republik Indonesian.

Penelitian ini juga menunjukkan beberapa keterbatasan sehingga pada penelitian selanjutnya dapat disarankan untuk mempertimbangkan prediktor lainnya yang dapat mempredikasi ideologi politik berbasis agama seperti variabel yang terkait agama seperti tingkat religiusitas, 
fundamentalisme, dan orientasi religius. Selain itu sesuai dengan kerangka teori yang dipakai dual process model dan kerangka ideologi-motivasional perlu mempertimbangkan variabel moderator atau mediator seperti adanya ancaman, Selain itu, untuk mendapatkan hasil pengukuran yang lebih baik mengenai tipe kepribadian Big Five sebaiknya menggunakan versi yang lebih lengkap. Versi pendek masih dipertanyakan kekuatan psikometriknya. Hal lain yang perlu diperhatikan adalah mengenai ideologi politik berbasis agama, mengingat agama Islam adalah agama yang bersifat orthopraxy sehingga ideologi tidak hanya kepercayaan dalam bidang politik namun dapat dilihat lebih detail kepercayaan dalam bidang ekonomi dan bidang kehidupan lainnya.

\section{References}

Akhtar, H. (2018). Translation and validation of the Ten-Item Personality Inventory (TIPI) into Bahasa Indonesia. International Journal of Research Studies in Psychology, 7(2), 59-69. https://doi.org/10.5861/ijrsp.2018.3009

Duckitt, J., \& Sibley, C. G. (2010). Personality, ideology, prejudice, and politics: A dual-process motivational model. Journal of Personality, 78(6), 1861-1894. https://doi.org/10.1111/j.14676494.2010.00672.x

Fauzia, A., Prihatna, A. A., Abubakar, I., Muchtadlirin, Al-Makassary, R., Pranawati, R., ... Kamil, S. (2011). Islam di Ruang Publik: Politik Identtas dan Masa Depan Demokrasi di Indonesia. (N. Hasan \& I. Abubakar, Eds.). Jakarta: Center for the Study of Religion and Culture.

Hennes, E. P., Nam, H. H., Stern, C., \& Jost, J. T. (2012). Not All Ideologies are Created Equal: Epistemic, Existential, and Relational Needs Predict System-Justifying Attitudes. Social Cognition, 30(6), 669-688. https://doi.org/10.1521/soco.2012.30.6.669

Jost, J. T. (2006). The End of the End of Ideology. American Psychologist, 61(7), 651-670. https://doi.org/10.1037/0003-066X.61.7.651

Jost, J. T., Federico, C. M., \& Napier, J. L. (2009). Political Ideology: Its Structure, Functions, and Elective Affinities. Annual Review of Psychology, 60(1), 307-337. https://doi.org/10.1146/annurev.psych.60.110707.163600

Jost, J. T., Glaser, J., Kruglanski, A. W., \& Sulloway, F. J. (2003). Political conservatism as motivated social cognition. Psychological Bulletin, 129(3), 339-375. https://doi.org/10.1037/0033-2909.129.3.339

Jost, J. T., Hawkins, C. B., Nosek, B. a., Hennes, E. P., Stern, C., Gosling, S. D., \& Graham, J. (2013). Belief in a just God (and a just society): A system justification perspective on religious ideology. Journal of Theoretical and Philosophical Psychology, 34(1), 56-81. https://doi.org/10.1037/a0033220

Jost, J. T., Ledgerwood, A., \& Hardin, C. D. (2008). Shared Reality, System justification, and the Relational Basis of Ideological Beliefs. Social and Personality Psychology Compass, 2(1), 171-186. https://doi.org/10.1111/j.1751-9004.2007.00056.x

Jost, J. T., Napier, J. L., Thorisdottir, H., Gosling, S. D., Palfai, T. P., \& Ostafin, B. (2007). Are needs to manage uncertainty and threat associated with political conservatism or ideological extremity? Personality and Social Psychology Bulletin, 33(7), 989-1007. https://doi.org/10.1177/0146167207301028 
Jugert, P., Cohrs, J. C., \& Duckitt, J. (2009). Inter- and Intrapersonal Processes Underlying Authoritarianism: The Role of Social Conformity and Personal Need for Structure. European Journal of Personality, 23(June), 607-621. https://doi.org/10.1002/per

Leary, M. R., Kelly, K. M., Cottrell, C. A., \& Schreindorfer, L. S. (2013). Construct validity of the need to belong scale: Mapping the nomological network. Journal of Personality Assessment, 95(6), 610-624. https://doi.org/10.1080/00223891.2013.819511

Sakai, M., \& Fauzia, A. (2014). Islamic orientations in contemporary Indonesia: Islamism on the rise ? Asian Ethnicity, 15(1), 41-61. https://doi.org/10.1080/14631369.2013.784513

Saroglou, V. (2011). Believing, Bonding, Behaving, and Belonging. Journal of Cross-Cultural Psychology, 42(8), 1320-1340. https://doi.org/10.1177/0022022111412267

Sibley, C. G., Osborne, D., \& Duckitt, J. (2012). Personality and political orientation: Meta-analysis and test of a Threat-Constraint Model. Journal of Research in Personality, 46(6), 664-677. https://doi.org/10.1016/j.jrp.2012.08.002

Thorson, J. A., \& Powell, F. C. (1992). A revised death anxiety scale. Death Studies, 16(6), 507521. https://doi.org/10.1080/07481189208252595

Vail, K. E., Rothschild, Z. K., Weise, D. R., Solomon, S., Pyszczynski, T., \& Greenberg, J. (2010). A terror management analysis of the psychological functions of religion. Personality and Social Psychology Review, 14(1), 84-94. https://doi.org/10.1177/1088868309351165

Verhulst, B., Hatemi, P. K., \& Martin, N. G. (2010). The nature of the relationship between personality traits and political attitudes. Personality and Individual Differences, 49(4), 306316. https://doi.org/10.1016/j.paid.2009.11.013

Ysseldyk, R., Matheson, K., \& Anisman, H. (2010). Religiosity as Identity: Toward an Understanding of Religion From a Social Identity Perspective. Personality and Social Psychology Review, 14(1), 60-71. https://doi.org/10.1177/1088868309349693 